\title{
FOOD CHOICES AND KNOWLEDGE ABOUT DISEASES ASSOCIATED AMONG PRIVATE UNIVERSITY STUDENTS IN SHAH ALAM, MALAYSIA.
}

\author{
Yogesraj Selvamoney, Mohammed A. Abdalqader \\ International Medical School, Management and Science University, Selangor, Malaysia \\ Corresponding author: yogesraj6994@gmail.com
}

\begin{abstract}
Introduction: Diet related diseases are diseases in human body for a long period of time that is not dangerous and it can be preventable. This diet related diseases occur due to poor eating habits. Diet related diseases includes obesity, cardiovascular diseases, cancer, diabetes, osteoporosis, and dental diseases. Methods: A survey was carried out to discover the food choices and knowledge about diseases associated among Management and Science University students. For this research study, survey method was used to collect the data. The method used to collect data which is by questionnaire which is very effective and cost effective. The questionnaire was designed in simple manner, easy to read and easy to understand for the respondents and avoid any misunderstanding. Results: Most of the students which is 277 had poor knowledge in choosing food (69.3\%). Not only that, 123 students have good knowledge in choosing food (30.8\%). By this, we found out that most of the students have poor knowledge in choosing food. Moreover, 161 students have poor knowledge about diet related diseases (40.3\%). Moreover, 239 students have good knowledge about diet related diseases (59.8\%). students who have poor knowledge in choosing food which is 156 students have poor knowledge about diet related diseases as well (96.9\%). Only 5 students who are good in choosing food are having poor knowledge about diet related diseases (3.1\%). Moreover, 121 students who are poor in choosing food have a very good knowledge about diet related diseases (50.6\%). Whereas, 118 students who are good in choosing food have a very good knowledge about diet related diseases (49.4\%). Conclusion: By this, we found out that majority student have poor knowledge in choosing food and poor knowledge about diet related diseases.
\end{abstract}

Keywords:

MSU Students, Food Choice, Knowledge About Diet Related Diseases 


\section{Introduction}

Diet related diseases are diseases in

human body for a long period of time that is not dangerous and it can be preventable. This diet related diseases occur due to poor eating habits. Diet related diseases includes obesity, cardiovascular diseases, cancer, diabetes, osteoporosis, and dental diseases.(WHO, 2002). More than that, diet related diseases are major cause of death and disability. Cardiovascular diseases, diabetes, cancer, obesity, respiratory diseases, are amount for $59 \%$ of 57 million mortality annually and $46 \%$ of diseases that burden the global. Not only that, there is a relationship between dietary habits and diet related diseases. Moreover, if there is a modification in dietary habits and physical activity, there is a major impact in reduction of the rates of these diet related diseases. (WHO, 2005).

A total of $63.6 \%$ of the people who responded had a very low knowledge of diabetes, $27.2 \%$ had a fair knowledge about diabetes and only $9.3 \%$ had a very good knowledge about diabetes. More than that, $50.5 \%$ had a very poor knowledge about hypertension, 19.8\% had a very fair knowledge about hypertension, and $29.7 \%$ had a very good knowledge about hypertension. Moreover, $63.6 \%$ had a very poor knowledge about obesity, $27.2 \%$ had a fair knowledge about obesity and $9.3 \%$ had a very good knowledge about obesity. (Nti et al., 2012).

Nutritional needs are very high for both genders and dietary inadequacies in adolescence is high. More than that, development and rates of growth combined with appropriate psychosocial changes. (WHO, 2002). Moreover, eating patterns exist during the period of adolescence which may follow throughout the whole life cycle. (Stewart et al., 1995).

Nti, 2012 mentioned that $87.9 \%$ of people who responded ate three times in a day, $10.5 \%$ ate twice a day and $1.6 \%$ ate once in a day. More than that, $41.8 \%$ of respondents skipped breakfast, $16 \%$ of respondents skipped lunch, $1.9 \%$ of respondents skipped supper, $12 \%$ of respondents skipped snacks and $28.3 \%$ of respondents didn't skip any meals. There were many reasons respondents skipped the meal. Most of the respondents which is 94\% skipped their breakfast due to lack of time to eat. There is a lack of time due to they woke up late or late to school. More than that, $4 \%$ of the respondents felt uncomfortable after eating breakfast and that was one of the reason they stop eating breakfast. Not only that, breakfast was the most common mistake due to desire to sleep longer, lack of time and appetite. By skipping breakfast, the total daily energy, vitamins and minerals intakes are low compared to respondents who did not skip meals. (Nti et al., 2012).

Even though, university students have grown up, they still face some nutritional problems during this stage. Some students may eat a lot but they remain their body size. But, some students they eat less, but they put a lot of weight. This can be due to body metabolism and the way the body reacts to food. This can be a reason some students eat a lot and some students eat very less. Overeating or not eating at all can result in obesity and diabetes as well. The overall prevalence for obesity and overweight is high and the prevalence of obesity and overweight is higher in boys compared to girls. Some of them may don't have the knowledge about nutrition value in food which can lead to certain diet related diseases.

To sort this problem out, parents should bring their children to a regular medical check-up to see their health status. Parents or guardian should ask the physician about their children's health. Another way to solve this problem is by checking Body Mass Index used by medical personnel and can be done by ourselves as well. This is one of the solutions to prevent obesity. Last but not least, students are suggested to look or review on calorie requirements that is needed for their body and some nutritional guidelines which may benefit them and leave a healthy lifestyle.

The objectives of the study is to discover the food choices and the knowledge of diseases associated among Management and Science University Students. 


\section{Methods}

The target population used for this research is Management and Science University Students age between 18 to 45 years old. This research finds the food choice and knowledge about diseases associated among students in the following age range who study in Management and Science University. The objective of the study was to discover the food choices and the knowledge of diseases associated among Management and Science University Students. This research involves convenience sampling method where the population is obtained in Management and Science University. Convenience sampling is a type of sample which has non- probability sampling where the target population has certain criteria such as accessibility, geographical, availability and willingness for the purpose of study. (Dornyei, 2007). The target respondents are foundation, diploma, undergraduate and post graduate student. The total sample size was 400 respondents. Few previous articles were used to obtained the sample size. The sample size was obtained by using two population proportion formula. Moreover, the calculation was done using each specific objective. Out of all the calculation for each objective, the highest sample size which is 345 was obtained from a objective which is "To study the relationship between knowledge about diet related diseases and socio demographic factors". Another 55 was added to the sample size to get a round number.

\section{Data Collection Procedure}

The data collection process involves collecting respondent's opinions and getting useful information from participants for the research questions stated. (Cooper et al., 2003). From the literature review, the most important method used to collect data was done using questionnaires. The use of questionnaire gives an advantage which is cost effective, easy to analyse, familiar, bias and less intrusive. A complete questionnaire which was taken from UCL which is a website where we can get questionnaires for nutrition knowledge which is titled "General Nutrition Knowledge Questionnaire or GNKQ" is printed for 400 respondents. The questionnaire took almost 10 minutes to complete which has total of 3 sections which is sociodemographic survey, food choice and knowledge about diet related diseases. The data was collected between September and October 2018. The survey was approved by the ethics committee of MSU Research and Development. Moreover, informed consent was collected from all the students which was attached in front of the questionnaire. A total of $400 \mathrm{MSU}$ students participated to complete the 8 pages of questionnaire.

\section{Survey Instrument}

The method used to collect data which is by questionnaire which is very effective and cost effective. The questionnaire shows a very organized and method that is effective to collecting data, asking questions, factor of interest and accuracy. (Sekaran et al., 2009). The questionnaire is designed in simple manner, easy to read and easy to understand for the respondents and avoid any misunderstanding. Moreover, participants are informed that the research is done to study the food choice and knowledge about disease associated. Approximately 43 questions are developed by modifying the questionnaires based on the objectives of the study. More than that, the questionnaire has total of 3 sections. In the first section, participants have to fill up their sociodemographic profile such as age, race, weight, height, race and health perception. Secondly, part 2 consist of questions about food choice knowledge which is healthy and unhealthy. Lastly, part 3 consist of questions about knowledge about diet related diseases.

\section{Ethical Consideration}

Permission was obtained from concerned authorities of Management and Science University, Shah Alam. An informed verbal consent will be taken from each participant prior to data collection. Participation will be completely voluntary and participants will be allowed to withdraw at any time without any repercussions. Other than that, confidentiality will be maintained throughout the entire course of this research. 


\section{Results}

First of all, study about food choice of MSU students was done. According to the data analysis, most of the students which is 277 had poor knowledge in choosing food (69.3\%). Not only that, 123 students have good knowledge in choosing food $(30.8 \%)$. Moreover, we also discovered the level of knowledge about diet related diseases among MSU students. It shows that, 161 students have poor knowledge about diet related diseases (40.3\%). Moreover, 239 students have good knowledge about diet related diseases $(59.8 \%)$.

Secondly, the relationship between food choices and knowledge about diet related diseases among MSU students. According to the data analysis, students who have poor knowledge in choosing food which is 156 students have poor knowledge about diet related diseases as well $(96.9 \%)$. Only 5 students who are good in choosing food are having poor knowledge about diet related diseases (3.1\%). Moreover, 121 students who are poor in choosing food have a very good knowledge about diet related diseases (50.6\%). Whereas, 118 students who are good in choosing food have a very good knowledge about diet related diseases (49.4\%). By this, we found out that majority student have poor knowledge in choosing food and poor knowledge about diet related diseases.

Not only that, food choice was compared with student's social demographic profile such as gender, race, faculty and health perception. First of all, the relationship between food choice and gender of MSU students was tested. It shows that 96 of male students have poor knowledge in choosing food $(71.6 \%)$. Not only that, 38 male students have good knowledge in choosing food (28.4\%). Moreover, female students also participated in this survey. The data analysis found out that 181 female students were having poor knowledge in choosing food (68.0\%). Then, 85 female students were having good knowledge in choosing food. (32.0\%). Moreover, the relationship between food choice and races of MSU students was tested. We found out that 93 Malay students have poor knowledge in choosing food (60.0\%). Not only that, 62 Malay students are good in choosing food that is healthy for them (40.0\%). Moreover, 57
Chinese students were having poor knowledge in choosing food (66.3\%). Then, 29 Chinese students have poor knowledge in choosing food that is healthy for him $(33.7 \%)$.

If we look at Indian students, 106 Indian students have poor knowledge in choosing food (79.1\%). Where else, 28 Indian students are good in choosing food that is healthy for them (20.9\%). Lastly, 21 of other races students were having poor knowledge in choosing food $(84.0 \%) .4$ of other races students were having good knowledge in choosing food (16.0\%).

By this we found out that, majority students of different races have poor knowledge in choosing food that is healthy for them which includes Malay, Chinese, Indian and others.

After that, the relationship between food choice and faculty of MSU students was tested. The analysis shows that 25 FBMP students are poor in choosing food that is healthy for them (75.8\%). Moreover, 8 students from FBMP are having good knowledge in choosing food (24.2\%). Not only that, FHLS student also participated in this research. The analysis shows that $5 \mathrm{FHLS}$ students are poor in knowledge of choosing food that is healthy $(62.5 \%)$. Where else, 3 FHLS students are good in choosing food that is healthy for them (37.5\%). FISE students also joined this study. It showed that, 57 FISE students are having poor knowledge in choosing food that is healthy for them (85.1\%). Moreover, 10 FISE students only have good knowledge in choosing food that is healthy for them (14.9\%). Now, we take a look at IMS students' statistics. It shows that 103 IMS students have poor knowledge in choosing food $(66.5 \%)$ ) 52 IMS students are good in choosing food that is healthy for them (33.5\%). SESS faculty students also joined this research. The data analysis showed that 40 SESS students have poor knowledge in choosing food $(75.5 \%)$, where else, 13 SESS students are good in choosing food that is healthy for them (24.5\%). Moreover, now we take a look at SHCA faculty students' statistics. 21 SHCA students are having poor knowledge in choosing food (95.5\%). Only 1 SHCA students have a good knowledge in choosing food that is healthy for them (4.5\%). Lastly, SPH students were also involved in this research study. It shows that $26 \mathrm{SPH}$ students are having poor knowledge in choosing food that is healthy 
for them (41.9\%), $36 \mathrm{SPH}$ students are having good knowledge in choosing food with health concern $(58.1 \%)$. By this we got to know that most of the faculty students have poor knowledge in choosing food except for SPH students where $(58.1 \%)$ of the students have good knowledge in choosing food and $(41.9 \%)$ of the students have poor knowledge about healthy food choice. Lastly, the relationship between food choice and health perception was tested. 16 students who have poor health perception are also poor in choosing food that is healthy for them as well (88.9\%). Moreover, 2 students with poor health perception only are good in choosing food that is healthy (11.1\%). Now, we move on to students who have fair health perception. The analysis shows that 59 students with fair health perception are poor in choosing food that is healthy $(60.2 \%)$. On the other side, 39 students with fair health perception are good in choosing food that is healthy for them. 148 students with good health perception are poor in choosing food that is healthy for them $(70.8 \%) .61$ students with good health perception are good in choosing food that is healthy for them (29.2\%). Moreover, 39 students who have very good health perception are having poor knowledge in choosing food that is healthy for them (70.9\%). 16 students with a very good health perception are very good in choosing food that is healthy for them (29.1\%). Lastly, 15 students with excellent health perception are very poor in choosing food that is healthy for them (75.0\%). 5 students with excellent health perception are having good knowledge in choosing food (25.0\%). By this we can found out that most of the students with different health perception which includes poor, fair, good, very good and excellent health perception are having poor knowledge in choosing food $(69.3 \%)$. The others are having good knowledge in choosing food (30.8\%).

Next, the relationship between knowledge about diet related diseases and social demographic factors. Level of knowledge about diet related diseases of students was compared with student's social demographic profile such as gender, race, faculty and health perception. First of all, the relationship between knowledge about diet related diseases and gender of MSU students. The analysis found out that 59 of male students have poor knowledge about diet related diseases (44.0\%). Not only that, 75 male students have good knowledge about diet related diseases (56.0\%). Moreover, female students also participated in this survey. The data analysis found out that 102 female students were having poor knowledge about diet related diseases (38.3\%). Then, 164 female students were having good knowledge about diet related diseases (61.7\%). Moreover, the relationship between knowledge about diet related diseases and races of MSU students was tested. The data analysis found out that 45 Malay students have poor knowledge about diet related diseases (29.0\%). Not only that, 110 Malay students have good knowledge about diet related diseases that (71.0\%). Moreover, 37 Chinese students were having poor knowledge about diet related diseases (43.0\%). Then, 49 Chinese students have poor knowledge about diet related diseases (57.0\%). If we look at Indian students, 68 Indian students have poor knowledge about diet related diseases (50.7\%). Where else, 66 Indian students have good knowledge about diet related diseases (49.3\%). Lastly, 11 of other races students were having poor knowledge about diet related diseases (44.0\%). 14 of other races students were having good knowledge about diet related diseases (56.0\%). By this we found out that, majority students of different races have poor knowledge about diet related diseases which includes Malay, Chinese, Indian and others.

Next, the relationship between knowledge about diet related diseases and faculty of MSU students. It shows that that 10 FBMP students have poor knowledge about diet related diseases (30.3\%). Moreover, 23 students from FBMP are having good knowledge about diet related diseases (69.7\%). Not only that, FHLS student also participated in this research. The analysis shows that 5 FHLS students are poor in knowledge about diet related diseases (62.5\%). Where else, 3 FHLS students are having good knowledge about diet related diseases $(37.5 \%)$. FISE students also joined this study. It showed that, 42 FISE students are having poor knowledge about diet related diseases (62.7\%). Moreover, 25 FISE students only have good knowledge about diet related diseases (37.3\%). Now, we take a look at IMS students' statistics. It shows that 42 IMS 
students have poor knowledge about diet related diseases (27.1\%). 113 IMS students are having good knowledge about diet related diseases $(72.9 \%)$. SESS faculty students also joined this research. The data analysis showed that 35 SESS students have poor knowledge about diet related diseases $(66.0 \%)$, where else, 18 SESS students are having good knowledge about diet related diseases (34.0\%). Moreover, now we take a look at SHCA faculty students' statistics. 15 SHCA students are having poor knowledge about diet related diseases (68.2\%). Only 7 SHCA students have a good knowledge about diet related diseases (31.8\%). Lastly, SPH students were also involved in this research study. It shows that 12 SPH students are having poor knowledge about diet related diseases (19.4\%), $50 \mathrm{SPH}$ students are having good knowledge about diet related diseases (80.6\%). Lastly, the relationship between knowledge about diet related diseases and health perception of MSU students was observed. 13 students who have poor health perception are also have poor knowledge about diet related diseases (72.2\%). Moreover, 5 students with poor health perception only have good knowledge about diet related diseases $(27.8 \%)$. Now, we move on to students who have fair health perception. The analysis shows that 38 students with fair health perception have poor knowledge about diet related diseases $(38.8 \%)$. On the other side, 60 students with fair health perception have good knowledge about diet related diseases (61.2\%). 80 students with good health perception have poor knowledge about diet related diseases (38.3\%). 129 students with good health perception have good knowledge about diet related diseases $(61.7 \%)$. Moreover, 24 students who have very good health perception are having poor knowledge about diet related diseases (43.6\%). 31 students with a very good health perception have very good knowledge about diet related diseases (56.4\%). Lastly, 6 students with excellent health perception have very poor knowledge about diet related diseases (30.0\%). 14 students with excellent health perception are having good knowledge about diet related diseases (70.0\%).

When we compared the knowledge about diet related diseases with age among MSU students. The $p$-value obtained was $(p=0.751)$.
Moreover, the $p$-value is $(>0.005)$. So, we can say that the association between knowledge about diet related diseases and age is not significant. When we compared the knowledge about diet related diseases with BMI among MSU students. The $p$-value obtained was $(p=$ $0.142)$. Moreover, the $p$-value is $(>0.005)$. So, we can say that the association between knowledge about diet related diseases and age is not significant.

\section{Table1 Association between Knowledge about diet related diseases and food choices}

\begin{tabular}{|c|c|c|c|c|}
\hline \multirow{2}{*}{$\begin{array}{l}\text { Knowledge about } \\
\text { diet related } \\
\text { diseases }\end{array}$} & \multicolumn{4}{|c|}{ Food Choice } \\
\hline & $\begin{array}{c}\text { poor } \\
\text { choosing } \\
\text { food }\end{array}$ & $\begin{array}{c}\text { good } \\
\text { choosing } \\
\text { food }\end{array}$ & $\mathrm{x}^{2}$ & $\begin{array}{c}p- \\
\text { value }\end{array}$ \\
\hline $\begin{array}{l}\text { Poor knowledge } \\
\text { about diet } \\
\text { related diseases }\end{array}$ & $\begin{array}{c}156 \\
(96.9 \%)\end{array}$ & $\begin{array}{c}5 \\
(3.1 \%)\end{array}$ & 96.70 & $<0.001$ \\
\hline $\begin{array}{l}\text { Good knowledge } \\
\text { about diet } \\
\text { related diseases }\end{array}$ & $\begin{array}{c}121 \\
(50.6 \%)\end{array}$ & $\begin{array}{l}118 \\
(49.4 \%)\end{array}$ & & \\
\hline Total & 277 & 123 & & \\
\hline
\end{tabular}

\section{Discussion}

In a previous research, there was a significant relationship between vegetable intakes in a high level and high knowledge about diet related diseases among children and their guardians as well (Keiko et al., 2017). According to previous research, only 12 percent of consumers know that there is relationship between sodium intake and hypertension $(\mathrm{NIH}$, 1981). 
According to previous research, it shows that both male and female are at risk of poor dietary habits, poor nutrition knowledge and awareness which affects their food choice and food preference (Suneetha et al., 2014). Moreover, previous research shows that males choose select taste, quality and cost as reason of food dislikes. Not only that, females consider health when buying food compared to male (Stacey et al., 2012).

Previous research shows that students of different races other than white choose taste, convenience and cost as reason to dislike the food (Stacey et al., 2012). In contrast, another research says that race was not an important factor in food choices among college students (Rozin et al., 2003).

According to previous research, $73.6 \%$ of students have an episode of gastroenteritis due to food choice (Bagordo et al., 2013). In contrast, it shows that fast food restaurant has an association with prevalence of diabetes which is significant relationship which is $p=$ 0.001 (Tarun et al., 2017). Another research showed that fast food intake which is high was significant among obese or overweight students. Moreover, it says that $72.5 \%$ of students choose fast food more than 4 times a week and some take daily as morning snack (Monira et al., 2014).

\section{Conclusion}

The alternative hypothesis is accepted. There is significant relationship between food choice and knowledge about diet related disease among Management and Science University students. Moreover, there is significant relationship between food choices and social demographic factors among Management and Science University students. Lastly, there is significant relationship between knowledge about diet related diseases and social demographic factors among Management and Science University students.

\section{References}

Aldallal, S. (2016). Iron Deficiency Anaemia: A Short Review, 2(1), 1-6. Retrieved from https://www.omicsonline.org/openaccess/iron-deficiency-anaemia-a-shortreview-.pdf
An Investigation of Food Choice Behaviour and Dietary Intake of Children, Teenagers. (2013), (May).

Ares, G., Machín, L., Girona, A., Curutchet, M. R., \& Giménez, A. (2017). Comparison of motives underlying food choice and barriers to healthy eating among low medium income consumers in Uruguay. Cadernos de Saúde Pública, 33(4), 1-12. https://doi.org/10.1590/0102$311 \times 00213315$

Asma, A., Nawalyah, A. G., Rokiah, M. Y., \& Mohd Nasir, M. T. (2010). Comparison of food choice motives between malay husbands and wives in an urban community. Malaysian Journal of Nutrition, 16(1), 69-81.

Bargiota, A., Pelekanou, M., Tsitouras, A., \& Koukoulis, G. N. (2013). Eating habits and factors affecting food choice of adolescents living in rural areas. Horm Behav., 12(2), 246-253. https://doi.org/10.14310/horm.2002.1408

Bhatta, M. P., Assad, L., \& Shakya, S. (2014). Socio-demographic and dietary factors associated with excess body weight and abdominal obesity among resettled Bhutanese refugee women in Northeast Ohio, United States. International Journal of Environmental Research and Public Health, 11(7), 6639-6652. https://doi.org/10.3390/ijerph110706639

Brewer, N. T., Ph, D., Weinstein, N. D., Cuite, C. L., \& Med, A. B. (2004). Risk Perceptions and Their Relation to Risk Behavior. Annals of Behavioral Medicine, 7(2), 125-130. https://doi.org/10.1207/s15324796abm27 02

Cavalli-Sforza, L. T., Rosman, A., De Boer, A. S., \& Darnton-Hill, I. (1996). Nutritional aspects of changes in disease patterns in the Western Pacific Region. Bulletin of the World Health Organization, 74(3), 307318. 
Contento, I. R. (2011). Overview of determinants of food choice and dietary change: Implications for nutrition education. Nutrition Education: Linking Research, Theory and Practice, 26-42.

De Mattos, B. R. R., Garcia, M. P. G., Nogueira, J. B., Paiatto, L. N., Albuquerque, C. G., Souza, C. L., ... Simioni, P. U. (2015). Inflammatory bowel disease: An overview of immune mechanisms and biological treatments. Mediators of Inflammation, 2015(August).

https://doi.org/10.1155/2015/493012

Delaney, M., \& Mccarthy, M. (2011). Journal of Food Products Marketing Food Choice and Health across the Life Course: A Qualitative Study Examining Food Choice in Older Irish Adults A Qualitative Study Examining Food Choice in Older Irish Adults, (April 2013), 37-41. https://doi.org/10.1080/10454446.2011.5 48717

Elnajeh, M. (2016). Dietary habits, nutritional knowledge and physical activity among Selangor matriculation students. 8th National Public Health Conference, (August).

Feunekes, G. I. J., de Graaf, C., Meyboom, S., \& van Staveren, W. A. (1998). Food Choice and Fat Intake of Adolescents and Adults: Associations of Intakes within Social Networks. Preventive Medicine, 27(5), 645-656. https://doi.org/10.1006/PMED.1998.0341

Fildes, A., Jaarsveld, C. H. M. Van, Llewellyn, C. H., Fisher, A., Cooke, L., \& Wardle, J. (2014). Nature and nurture in children's food preferences. The American Journal of Clinical Nutrition..., 99(1), 911-917. https://doi.org/10.3945/ajcn.113.077867.I NTRODUCTION

Food, U. (2006). What influences food choice? What influences repeated healthy, (April).

Ghazi, H. F., Elnajeh, M., AbdalQader, M., Baobaid, M. F., \& Omar, A. Bin. (2017).
Prevalence of hypertension and its association with nutritional factors among university students in Shah Alam, Malaysia. Pakistan Journal of Nutrition, 16(7), 544-549. https://doi.org/10.3923/pjn.2017.544.549

Grech, A., Sui, Z., Siu, H., Zheng, M., AllmanFarinelli, M., \& Rangan, A. (2017). SocioDemographic Determinants of Diet Quality in Australian Adults Using the Validated Healthy Eating Index for Australian Adults (HEIFA-2013). Healthcare, 5(1), 7. https://doi.org/10.3390/healthcare501000 7

Guthrie, J., Derby, B., \& Levy, A. (1999). What People Do and Do Not Know About Nutrition. America' Eating Habits: Changes and Consequences, (Agriculture Information Bulletin No. 750 (\{AIB\}-750)), 243-280.

Habib, M. A., Black, K., Soofi, S. B., Hussain, I., Bhatti, Z., Bhutta, Z. A., \& RaynesGreenow, C. (2016). Prevalence and predictors of iron deficiency anemia in children under five years of age in Pakistan, a secondary analysis of National Nutrition Survey data 2011-2012. PLOS ONE, 11(5), 1-13. https://doi.org/10.1371/journal.pone.0155 051

Hardcastle, S. J., Thøgersen-Ntoumani, C., \& Chatzisarantis, N. L. D. (2015). Food choice and nutrition: A social psychological perspective. Nutrients, 7(10), 8712-8715. https://doi.org/10.3390/nu7105424

Hawkes, C. (n.d.). Globalization and Health Uneven dietary development: linking the policies and processes of globalization with the nutrition transition, obesity and diet-related chronic diseases. https://doi.org/10.1186/1744-8603-2-4

Jpi-, T., Programming, J., \& Diet, I. (2009). Health, food and prevention of diet related diseases, 1-16. 
Kelder, S. H., Leslie, C. L., \& Lytle, L. (n.d.). Longitudinal Tracking of Adolescent Smoking, Physical Activity, and Food Choice Behaviors. Retrieved from https://ajph.aphapublications.org/doi/pdf/ 10.2105/AJPH.84.7.1121

Lindmark, U., Stegmayr, B., Nilsson, B., Lindahl, B., \& Johansson, I. (2005). Food selection associated with sense of coherence in adults. Nutrition Journal, 4 , 1-5. https://doi.org/10.1186/1475-2891-44

Lobstein, T., Jackson-Leach, R., Moodie, M. L., Hall, K. D., Gortmaker, S. L., Swinburn, B. A., ... McPherson, K. (2015). Child and adolescent obesity: part of a bigger picture. The Lancet, 385(9986), 25102520 . https://doi.org/10.1016/S01406736(14)61746-3

Lowry, R., Galuska, D. A., Fulton, J. E., Wechsler, H., Kann, L., \& Collins, J. L. (2000). Physical activity, food choice, and weight management goals and practices among U.S. college students. American Journal of Preventive Medicine, 18(1), 18-27. https://doi.org/10.1016/S07493797(99)00107-5

Mello, A. de C., Engstrom, E. M., \& Alves, L. C. (2014). Health-related and sociodemographic factors associated with frailty in the elderly: a systematic literature review. Cadernos de Saúde Pública, 30(6), 1143-1168. https://doi.org/10.1590/0102$311 \times 00148213$

Milošević, J., Žeželj, I., Gorton, M., \& Barjolle, D. (2012). Understanding the motives for food choice in Western Balkan Countries. Appetite, 58(1), 205-214. https://doi.org/10.1016/j.appet.2011.09.0 12

Missagia, S. V., Oliveira, S. R. De, \& Rezende, D. C. De. (2012). Food Choice Motives and Healthy Eating : Assessing Gender differences. XXXVI Encontro Da ANPAD, 1-13.
Murimi, M., Chrisman, M., McCollum, H., \& Mcdonald, O. (2016). A Qualitative Study on Factors that Influence Students' Food Choices. Journal of Nutrition and Health, (August).

Negri, R., Di Feola, M., Di Domenico, S., Scala, M. G., Artesi, G., Valente, S., ... Greco, L. (2012). Taste perception and food choices. Journal of Pediatric Gastroenterology and Nutrition, 54(5), 624-629.

https://doi.org/10.1097/MPG.0b013e3182 473308

Nestle, M., Wing, R., Birch, L., DiSogra, L., Drewnowski, A., Middleton, S., ... Economos, C. (2009). Behavioral and Social Influences on Food Choice. Nutrition Reviews, 56(5), 50-64. https://doi.org/10.1111/j.17534887.1998.tb01732.x

Nic Gabhainn, S., Kelleher, C. C., Naughton, a M., Carter, F., Flanagan, M., \& McGrath, M. J. (1999). Socio-demographic variations in perspectives on cardiovascular disease and associated risk factors. Health Education Research, 14(5), 619-628. https://doi.org/10.1093/her/14.5.619

Nti, C. A., Brown, A., \& Danquah, A. (2012). Adolescents' Knowledge of Diet-Related Chronic Diseases and Dietary Practices in Ghana. Food and Nutrition Sciences, 03(11), 1527-1532. https://doi.org/10.4236/fns.2012.311199

National Institutes of Health, National Heart, Lung, and Blood Institute. The Public and High Blood Pressure. Bethesda, MD. NIH publication 81-2118, 1981.

Republic, C., \& Activity, P. (2006). Resolution on Nutrition, Obesity and Diet-Related Disease, 6-9.

Riaz, S. (2009). Diabetes mellitus. Scientific Research and Essay, 4(5), 367-373. https://doi.org/10.2337/dc13-S067 
S, P. (2009). Iron Deficiency Anemia in moderate to severely anaemic patients.pdf. Gujarat Medical Journal. Retrieved from http://medind.nic.in/gaa/t09/i2/gaat09i2p1 5.pdf

Sbaraini, A., Evans, R. W., Kleinberg, I., Featherstone, J. D. B., Ribeiro, A. A., Carolina, N., ... Tiwle, R. (2016). Dental caries: A dynamic disease process. Australian Dental Journal, 53(4), 369377.

https://doi.org/10.15272/ajbps.v6i53.773

Sébastia, B., Balagopal, P., \& Misra, R. (2013). Diet-related diseases: Issues and solutions to nutrition transition and food programme policies in India Brigitte Sébastia, 1(c).

Sébastia, B., Balagopal, P., \& Misra, R. (2013). Diet-related diseases: Issues and solutions to nutrition transition and food programme policies in India Brigitte Sébastia, 1(c).

Shevherd, R. (1990). The psychology of food choice. Nutrition \& Food Science (Vol. 90). https://doi.org/10.1108/eb059291

The, I., \& Consultation, E. (1990). Diet, nutrition and chronic diseases in context. Lloydia (Cincinnati), 30-53.

Thiruselvakumar, D., Sinuvasan, K., R, S. C., \& Venkatesh, E. (2014). Factors affecting food choice and attitude of choosing food items among adolescents in South India. International Journal of Scientific and Research Publications, 4(4), 1-3.

Trew, K., Clark, C., Barnett, J., \& Uldoon, O. (2006). Adolescents, Food Choice and Vegetarianism. The Psychology of Food Choice, (October 2014), 247-262.

Vabø, M., \& Hansen, H. (2014). The Relationship between Food Preferences and Food Choice: A Theoretical. International Journal of Business and Social Science, 5(7), 145-157.
Van Vliet, B. N., \& Montani, J. P. (2008). The time course of salt-induced hypertension, and why it matters. International Journal of Obesity, 32(SUPPL. 6), 35-41. https://doi.org/10.1038/ijo.2008.181

vol. 22, no. 4 (supplement) @ 2001, The United Nations University. 31. (2001), 22(4), 3133.

W H O. (2005). Nutrition in adolescence Issues and Challenges for the Health Sector.

Weiss, G., \& Goodnough, L. (2005). Anemia of Inflammation and Chronic Disease. New England Journal of Medicine, 325(10), 1011-1023.

WHO. (2003). Diet, nutrition and the prevention of chronic diseases. World Health Organization Technical Report Series, 916, i-viii-1-149-backcover. https://doi.org/ISBN 924120916 X ISSN 0512-3054 (NLM classification: QU 145)

Willett, W. C., Koplan, J. P., Nugent, R., Puska, P., \& Gaziano, T. a. (2006). Chapter 44 Prevention of Chronic Disease by Means of Diet and Lifestyle Changes. Disease Control Priorities in Developing Countries (2nd Edition), (chapter 45), 833-850. 